\title{
An analysis of baffles designs for limiting impact on the directional response for a partially filled tank with agro-food liquids
}

\author{
Gabriela Milian ${ }^{1, *}$, Sorin-Ştefan Biriş $^{2}$, George Ipate $^{2}$, Alexandru Hristea $^{3}$, \\ Cristian Sorica ${ }^{1}$ and Florin Nenciu ${ }^{1}$ \\ ${ }^{1}$ INMA Bucharest, 6 Ion Ionescu de la Brad, 1st District, 013813, Romania \\ ${ }^{2}$ University "Politehnica" Bucharest, 313, Splaiul Independentei, 060042, Romania \\ ${ }^{3}$ INOE 2000-IHP, street Cutitul de Argint, no. 14, Sector 4, Bucharest, Romania
}

\begin{abstract}
A directional response for a partially filled tank with agro-food liquids incorporates the motion of the free surface due to roll and longitudinal accelerations into the dynamic tank model. This paper presents an analysis of efficaciousness of different designs of baffles for two different tank, to limit the impact of the response given by the liquid on the tank walls. In this paper modelling of the behaviour of the cross-section circular and ellipsoidal tank with baffles, partially filled with liquids agro-food, was developed, which performs a braking-in-a-turn manoeuver. Two different tank truck models have been used to simulate the sloshing effect of agro-food liquid cargo. Is also studied the two geometric models of the tank was done by using SolidWorks and simulating the behaviour of the tank ANSYS-CFX.

In this study, there were simulated and modeled two models of tank-type "X", respectively type "Y" used for the storage and transport of liquid agro-food products, namely water, for different speeds $(\mathrm{v}=14 \mathrm{~m} / \mathrm{s}$ and $\mathrm{v}=20 \mathrm{~m} / \mathrm{s})$ and two filling levels of the tank trucks ( $40 \%$ and $80 \%)$. The results obtained were compared the behaviour of the tank partially filled into a braking-in-a-turn manoeuver, in which the total values of the deformations that appear as a result of the impact due to the movement of the liquid inside the tank trucks.
\end{abstract}

Keywords: design baffles, impact on the directional response, Ansys-CFX

\section{Introduction}

As vehicles can move with partially filled tanks, there will inevitably be an interaction between vehicle movements and fluid, which are not always perceived by the driver. Thus, situations may occur where when the driver's action coincides with the action phase of the response given by the liquid contained on the tank so that its effect on the behaviour of the vehicle is amplified and may lead to overturning.

Under the action of external excitations (different displacement, loading/unloading manoeuvres), with large amplitude or near the natural frequency of the fluid sloshing inside

\footnotetext{
* Corresponding author: gabi isb@yahoo.com
} 
a partially filled tank, the fluid produces violent oscillations on the tank walls and the tank structure.

When the fluid interacts with the wall, the energy exchange takes place between the two liquid-solid structures, so that the fluid can exhibit different types of movements (longitudinal, transverse, chaotic) depending on the external excitation [1].

The movement of the fluid oscillation depends on the geometry of the tank, the filling conditions and the frequency range inside, that is, the quiet time of the fluid after the sloshing effect occurs Budiansky (1960). Besides, sloshing depends on the frequency and amplitude of the forces resulting from the movement Hasheminejad and Aghabeig (2011). If the frequency produced by the sloshing is close enough to the natural frequency of the fluid-structure, resonance will occur Ibrahim (1975). Also, stability is one of the most important purposes for the design of tank vehicles that transport and storage liquid agrofood products. [2, 3].

The purpose of studying the effect of sloshing, produced inside the tank for different geometrical constructive forms is to reduce the fatigue level, produced at the level of the structure of the tank material and to improve the design of the tank, for transporting the liquid cargo under optimal conditions.

From the determinations made by theoretical and experimental research it was found that the geometry of the container and the percentage of filling of the tank with liquid can directly affect the dynamic load transfer of the liquid, as well as the sloshing duration and the amplitude of the sloshing oscillation. In order to be able to reduce and control these factors, it was concluded that by installing baffles, the sloshing of the liquid in the longitudinal direction during the acceleration and braking of the vehicle can be limited [4, $5,6]$.

The results of the experimental and numerical research show that the dynamic directional responses of the vehicles with partially filled tanks obtain a special efficiency if the connection created between the sloshing and the tank vehicle is taken into account. Thus, the mounting and use of baffles of different shapes have proven to be most effective in suppressing the slosh force of the fluid under loading conditions [7-11].

\section{Materials and methods}

This study present an analise of the baffles design for limiting the impact regarding the steering control for a partial tank filled with agro-food liquid, more exactly of different designs of baffles for two different design tank model used to transport agro-food liquid cargo.

Two different tank truck models have been used to simulate the sloshing effect of agrofood liquid cargo. It is also explored the two geometric models of the tank using SolidWorks software, and the behaviour of the tank was simulated with ANSYS-CFX. Also, two models of tank ( type "X", respectively type "Y") were simulated and modeled, for the storage and transport of water, for different speeds $(\mathrm{v}=14 \mathrm{~m} / \mathrm{s}$ and $\mathrm{v}=20 \mathrm{~m} / \mathrm{s})$ and filling levels of the tank trucks $(40 \%$ and $80 \%)$.

The tank model " $\mathrm{X}$ " is presented in Figure 1 and it consists of a 3-dimensional fluids storage, with length $3840 \mathrm{~mm}$ and height $1300 \mathrm{~mm}$, with circular cross-section tank, and two baffles type (I) with height $1000 \mathrm{~mm}$. The tank model "Y" is presented in Figure 2, and has length $5370 \mathrm{~mm}$ and height $1300 \mathrm{~mm}$, with ellipsoidal cross-section tank with two baffles type (II) height $1300 \mathrm{~mm}$.

The influence of liquid motion on tank was performed with the help of ANSYS software (CFD-CFX- static and transient), and the 3D modelling using the Solidworks program. 
For tank model "X" with baffles type (I), CFD model is showed on Figure 3 and consist of 21673 nodes, of tetrahedral cell elements 114915. Also tank model "Y" with baffles type (II), CFD model is highlighted on Figure 4, with mesh tool 74377 nodes, of tetrahedral cell elements 36641 .

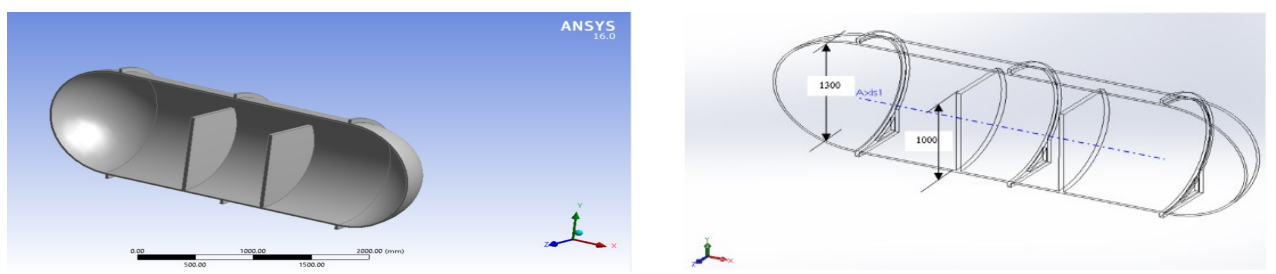

Fig.1.Physical model tanker "X" and geometrical design with baffles type (I)
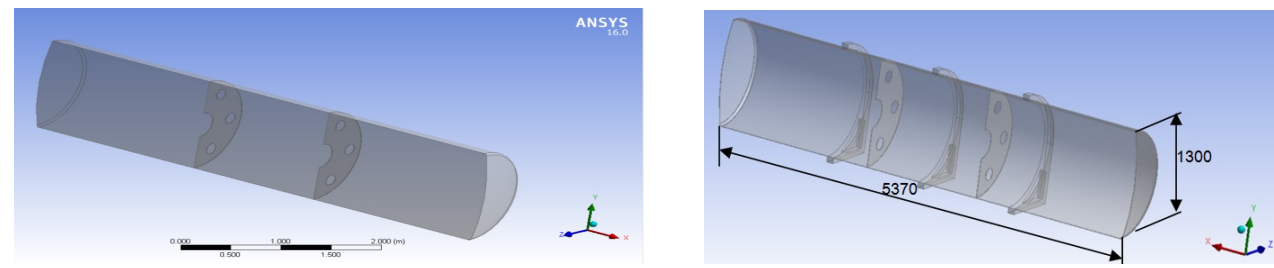

Fig.2. Physical model tanker "Y" and geometrical design with baffles type (II)
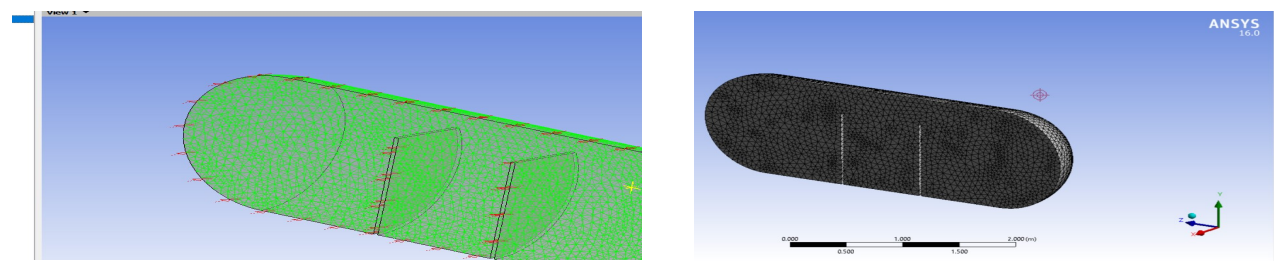

Fig.3. Mesh tanker and fluids for model tanker "X" with baffles type (I)
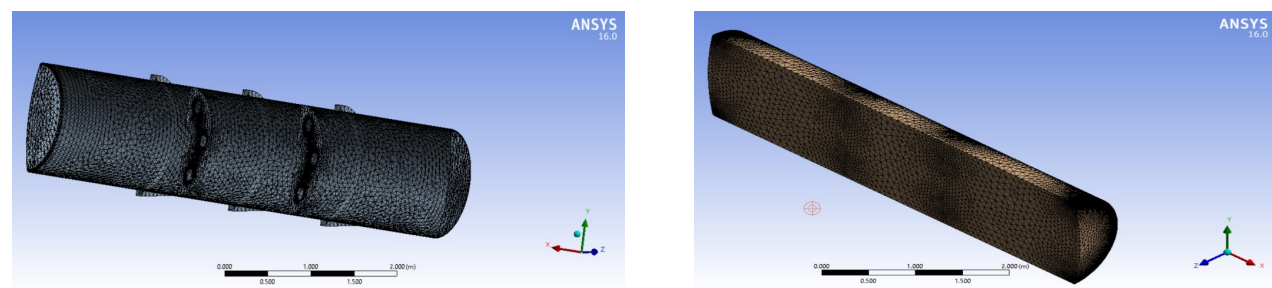

Fig.4. Mesh tanker and fluids for model tanker "Y" with baffles type (II)

The material used to make the walls of the two types of tanks "X" and $\mathrm{Y}$, as well as the baffles is carbon steel with a thickness of 3mm according to SR EN 10216-2[12].

Both the simulation of the "X" tank model as well as the "Y" tank model are done consecutively, for the two filling levels $40 \%$ and $80 \%$, respectively for the different speeds imposed by $\mathrm{v}=14 \mathrm{~m} / \mathrm{s}$ and $\mathrm{v}=20 \mathrm{~m} / \mathrm{s}$, which decrease in $10 \mathrm{sec}$. This time of $10 \mathrm{~s}$ represents the calming time of the fluid inside the tank.

Thus, in these cases, the deceleration simulates a sudden braking and stopping of the tank during a braking maneuver.

In both cases, for the two models the acceleration is performed for $5 \mathrm{sec}$, thus reaching an acceleration of $50 \mathrm{~km} / \mathrm{h}$ and $80 \mathrm{~km} / \mathrm{h}$, and the deceleration during the remaining $5 \mathrm{sec}($ braking) until the tank vehicle stops. 
The physico-chemical properties of the fluid simulated and studied for both tank, with the two types of baffles (type (I) and type (II)) are shown in Table 1, below:

Table 1.The specifications of the fluid agro-food simulation

\begin{tabular}{|r|c|c|c|c|}
\hline S.NO & NAME OF FLUID & NAME OF PROPERTY & VALUE & UNITS \\
\hline \multirow{2}{*}{1} & \multirow{2}{*}{ Water } & Density & 998.2 & $\mathrm{Kg} / \mathrm{m}^{3}$ \\
\cline { 3 - 5 } & & Viscosity & 0001003 & $\mathrm{Kg} / \mathrm{m}^{-1} \mathrm{~s}^{-1}$ \\
\hline
\end{tabular}

The simulation is based on the volume fraction (VOF) formula, thus forming the free surface inside the liquid tank (water-air). Having the following expression:

$$
\sum_{p=1}^{n} \alpha_{p}=1
$$

where : $\alpha_{\mathrm{p}}$ - volume fraction for those two fluids(water-air),

$\mathrm{n}$ - no of phases present in the computational cell,

p- fluids phase.

During the simulation of the two models of the tank with the two types of baffles it was considered that the temperature inside the vessels has the value of $20^{\circ} \mathrm{C}$, the pressure inside does not exceed the value of the atmospheric pressure. Thus, the models being in thermal equilibrium and in transient conditions with acceleration peak $1 \mathrm{~g}$ in the longitudinal direction.

\section{Results and discussion}

Further taking into account the values of the accelerations (of the speeds imposed), as well as of the simulation of the action time and the stabilization of the liquid, the displacement manoeuvres of the tank will result in the distribution of forces and stresses on the walls of the tank, the remaining deformation of the wall of the tank, the total deformation of the tank wall structure, both in static mode and in transient mode.

Starting from all this information in the paper are analyzed the simulation for :

a)The case in which the level of filling of the tank with water is $40 \%$ and it is required a speed $\mathrm{v}=14 \mathrm{~m} / \mathrm{s}$;

b)The case in which the level of filling of the tank with water is $40 \%$ and it is required a speed $\mathrm{v}=20 \mathrm{~m} / \mathrm{s}$;

c)The case in which the level of filling of the tank with water is $80 \%$ and it is required a speed $\mathrm{v}=14 \mathrm{~m} / \mathrm{s}$;

d)The case in which the level of filling of the tank with water is $80 \%$ and it is required a speed $\mathrm{v}=20 \mathrm{~m} / \mathrm{s}$;

The analysis will be highlighted below an analysis of baffles design for limiting impact on the directional response which is based on the volume fraction (VOF) formula, how fluid moves inside the tank, thus showing the shape of the free surface, the stresses and deformations that have occurred.

In case a) the two models of the tank are simulated in order to be able to observe the behaviour and the influence of the movement of the liquid on the walls of the tank. The behaviour is shown by highlighting the stresses and deformations that can be seen in Figures 5,6. 

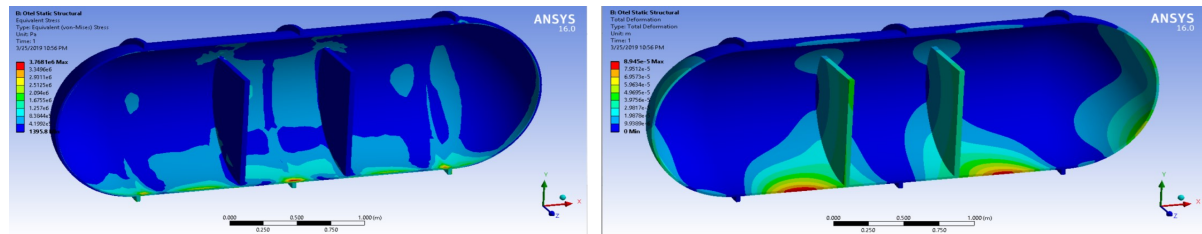

Fig.5. The result of the numerical simulation of the dynamic behavior of the fluid in the "X" type tank, with type (I) baffles for case a) for a speed $\mathrm{v}=14 \mathrm{~m} / \mathrm{s}$, time $10 \mathrm{~s}$, fill level $40 \%$;
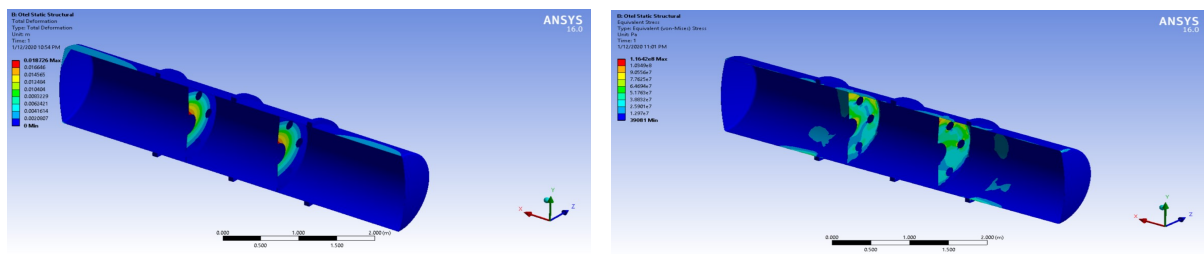

Fig.6. The result of the numerical simulation of the dynamic behavior of the fluid in the "Y" type tank, with type (II) baffles for case a) for a speed $\mathrm{v}=14 \mathrm{~m} / \mathrm{s}$, time $10 \mathrm{~s}$, fill level $40 \%$;

Simulations show the distributions of stresses and deformations that appear on the tank walls, both in static and dynamic (transient) conditions. The color white reproduce air, and blue the water. This is done in all cases according to the volume fraction (VOF) formula.

In the Figures of this paper, the total deformation of the tank structure is shown both in a static regime and in a transient area where the tank wall may suffer major damage, due to the very strong tension in those areas indicated by the numerical simulation by the red colour.

Further in the paper will be shown in the figures $(7,8,9,10,11,12)$ below results obtained from the simulation of the other three cases b), c) and d) for the two models of the tank with the two forms geometric constructions of baffles.
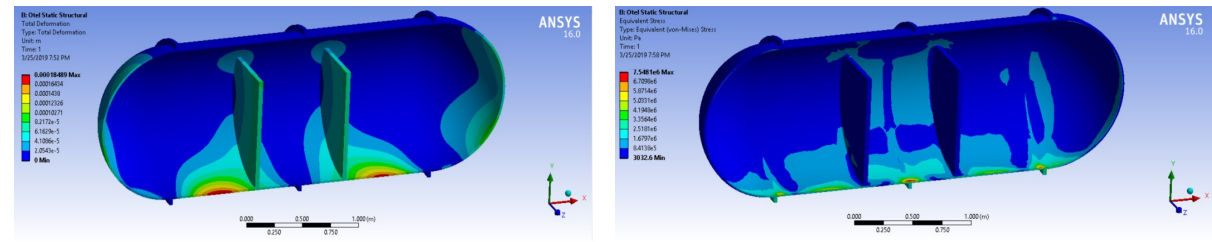

Fig.7. The result of the numerical simulation of the dynamic behavior of the fluid in the "X" type tank, with type (I) baffles for case b) for a speed $v=20 \mathrm{~m} / \mathrm{s}$, time $10 \mathrm{~s}$, fill level $40 \%$;
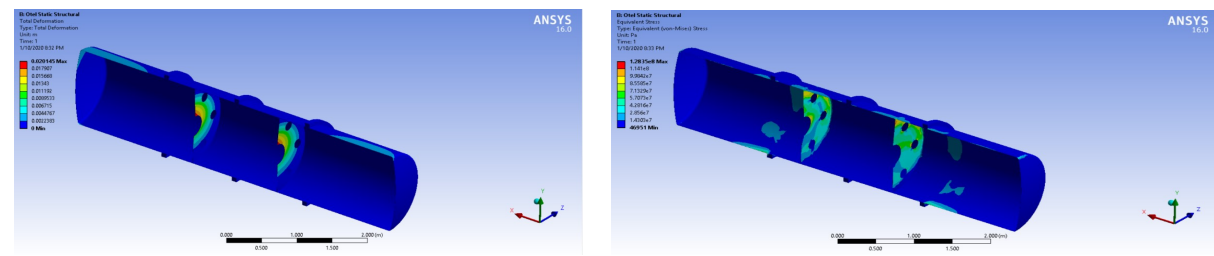

Fig.8. The result of the numerical simulation of the dynamic behavior of the fluid in the "Y" type tank, with type (II) baffles for case b) for a speed $\mathrm{v}=20 \mathrm{~m} / \mathrm{s}$, time $10 \mathrm{~s}$, fill level $40 \%$; 

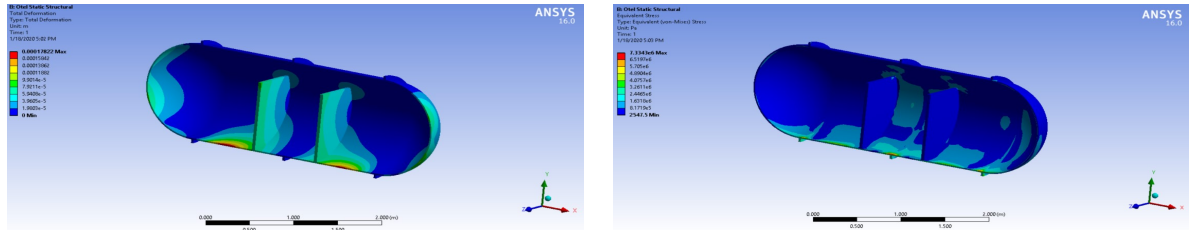

Fig.9. The result of the numerical simulation of the dynamic behavior of the fluid in the "X" type tank, with type (I) baffles for case c) for a speed $\mathrm{v}=14 \mathrm{~m} / \mathrm{s}$, time $10 \mathrm{~s}$, fill level $80 \%$;
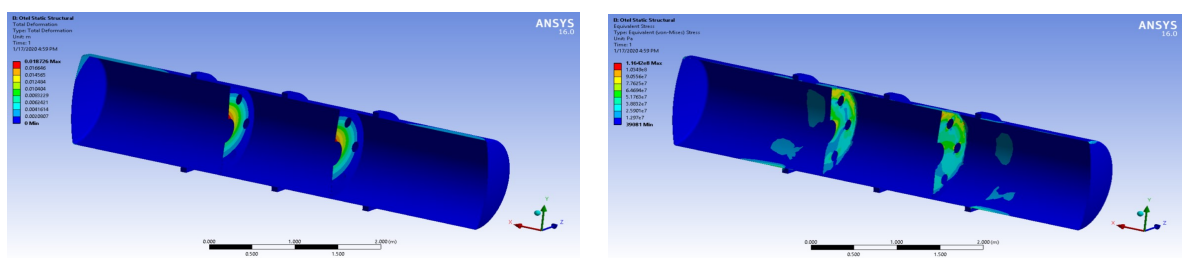

Fig.10. The result of the numerical simulation of the dynamic behavior of the fluid in the "Y" type tank, with type (II) baffles for case c) for a speed $\mathrm{v}=14 \mathrm{~m} / \mathrm{s}$, time $10 \mathrm{~s}$, fill level $80 \%$;
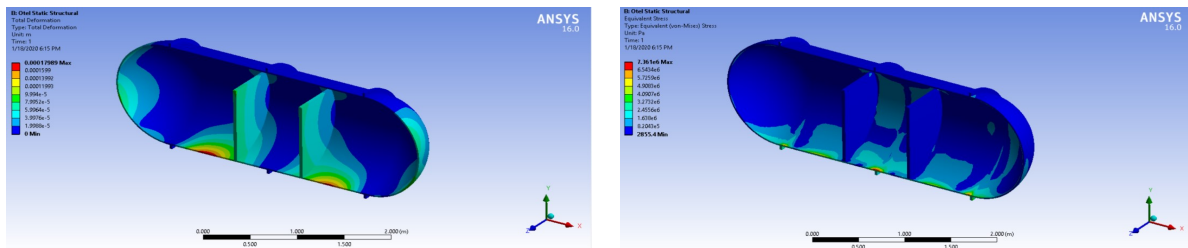

Fig.11. The result of the numerical simulation of the dynamic behavior of the fluid in the "X" type tank, with type (I) baffles for case d) for a speed $\mathrm{v}=20 \mathrm{~m} / \mathrm{s}$, time $10 \mathrm{~s}$, fill level $80 \%$;
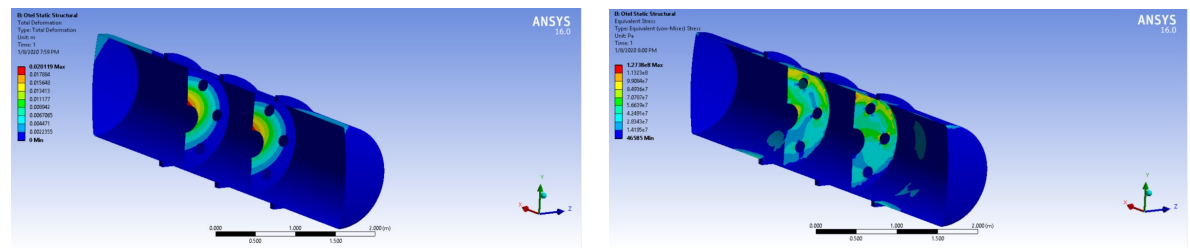

Fig.12. The result of the numerical simulation of the dynamic behavior of the fluid in the "Y" type tank, with type (II) baffles for case d) for a speed $\mathrm{v}=20 \mathrm{~m} / \mathrm{s}$, time $10 \mathrm{~s}$, fill level $80 \%$;

Thus, the pressure values in the two models of tank vehicle were reduced, even from the simulation, it is observed the rendering of higher pressures due to the resistance of the geometric shape of the baffles, which in time determines the damping of the voltages inside the tank vehicle as flat as seen in the figure 13.

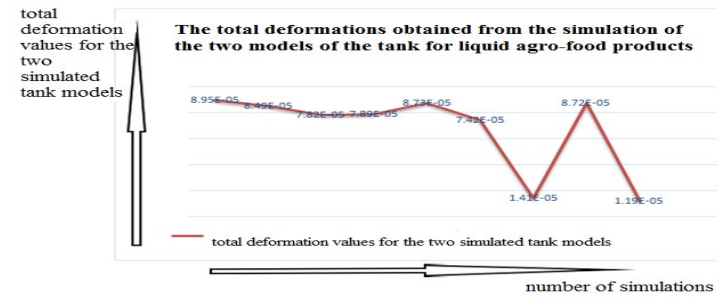

Fig.13. The result of the total deformation values for the two simulated tank models

By studying the two simulations for all four cases it was observed that the stresses on the walls of the tank tanks are higher for cases where the liquid level is lower in a case a) and $b$ ) for both tank models. 
The simulations also showed that the stresses and strains have much lower values in the case of the "Y" tank model with type II baffles, compared to the other model. This fact shows from the study that it is necessary and very important to mount similar models of baffles, with different constructive geometric shapes.

\section{Conclusion}

In conclusion this paper presents an analysis of efficaciousness of different designs of baffles for two different design tank models, in order to limit the impact of the response given by the liquid on the tank walls.

By simulating with the two geometrical constructive forms of the baffles inside the two tank models it has been shown that the baffles play an important role and that it reduces the stresses and deformations that appear on the tank wall structure.

Comparing the results obtained by simulating with different filling levels at different speeds when performing a braking manoeuvre it can be observed that the impact of the resulting fluid can create a damaging effect and that only by mounting those baffles can the stress of a disastrous danger be alleviated.

\section{References}

[1] R.Suyal, NIT Rourkela, n'213ME3440 (2016)

[2] R. Ranganathan,Thesis, Concordia University (1990)

[3] K. Modaressi-Terani, S.Rakheja,I Stiharu, VSD, 45 (2007)

[4] F. Sollas, Odd M. Faltisen, IJSR, 41 (1997)

[5] S. Rakheja , K. Modaressi-Terani , I Stiharu, VSD,45 (2007)

[6] X. Zheng, X.Li, Y.Ren, Y. Wang, J. Ma, Oc. Eng.,36, (2009)

[7] S. Rakheja, A. Kolaei, M. J. Richard, JSV, 70(2017)

[8] J. Zhang, W. Wu, J.Hu, J.Mar., 46,(2016)

[9] B.Nicolsen ,L.Wang, A.Shabana, JSV, 405 (2017)

[10]U.A. Siddiqui ,B. Fatima, H.U. Siddiqui, M Hammad, IJSR, 6 (2019)

[11]R.He , E.Zhang, B.Fan, JSAGE, 11, (2019)

[12] SR EN 10216-2 